\title{
Laparoscopic resection of extramucosal vesical endometriosis without partial cystectomy
}

\section{Ressecção laparoscópica de endometriose vesical extra-mucosa sem cistectomia parcial}

Kathiane Lustosa Augusto ${ }^{1}$, Thais Fontes de Magalhaes ${ }^{2}$, Flora Cruz de Almeida ${ }^{3}$, Leticia Matoso Freire Andreisa Paiva Monteiro Bilhar ${ }^{4}$, Leonardo Robson Pinheiro Sobreira Bezerra 5 .

1 Mestre em Ciências Médico-Cirúrgicas, Maternidade Escola Assis Chateaubriand (MEAC), Universidade Federal do Ceará (UFC), Fortaleza, Ceará, Brasil. 2 Mestre em Ciências Médico-Cirúrgicas, Universidade Federal do Ceará (UFC), Fortaleza, Ceará, Brasil. 3 Médica, Universidade Federal do Ceará (UFC), Fortaleza, Ceará, Brasil. 4 Doutora em Ginecologia, Maternidade Escola Assis Chateaubriand (MEAC), Universidade Federal do Ceará (UFC), Fortaleza, Ceará, Brasil. 5 Doutor em Ginecologia, Departamento de Saúde Materno-Infantil, Departamento de Cirurgia, Universidade Federal do Ceará (UFC), Fortaleza, Ceará, Brasil.

\section{ABSTRACT}

Bladder endometriosis is a rare condition that usually presents with cyclic urinary symptoms and pelvic pain. Its treatment generally involves surgery, which is usually done laparoscopically. In this case, we report the resection of vesical endometriosis without resecting the urothelium, thus avoiding partial cystectomy. This is a minimally invasive approach that should be considered in selected patients.

Keywords: Endometriosis. Laparoscopy. Urinary bladder.

\section{RESUMO}

A endometriose vesical é condição rara que comumente se apresenta com sintomas urinários cíclicos e dor pélvica. Seu tratamento geralmente envolve cirurgia, preferencialmente por via laparoscópica. Relatamos aqui o caso de ressecção de endometriose vesical sem atingir o urotélio, evitando assim a cistectomia parcial. Esta é uma abordagem minimamente invasiva que deve ser considerada em pacientes selecionados.

Palavras-chave: Endometriose. Laparoscopia. Bexiga urinária.

Corresponding Author: Thais Fontes de Magalhaes, Rua Alexandre Barauna, 949, Rodolfo Teófilo, Fortaleza, Ceará, Brasil. CEP: 60130-430. Telefone: +55 85 99700-5858. E-mail: thaisfdemagalhaes@gmail.com

Conflict of interests: The authors have no conflicts of interest to declare.

Received: 15 Aug 2017; Revised: 12 Oct 2017; Accepted: 18 Oct 2017. 


\section{INTRODUCTION}

Endometriosis is a benign gynecologic disorder characterized by the presence of endometrium-like tissue outside the uterine cavity, and may affect $10-15 \%$ of women of reproductive age, with increased prevalence in infertile women.,

The presence of the disease in the urinary tract is a rare condition, affecting around 1 to $5.5 \%$ of patients with endometriosis..$^{3-5}$ Although urinary tract lesions may occur in up to $52.6 \%$ of women with deep infiltrating disease, most of them present as ureteric endometriosis. ${ }^{6}$

Surgery remains the treatment of choice for women with urinary tract endometriosis. The laparoscopic approach is considered the gold standard due to its effectiveness and safety. ${ }^{5,6}$ In this report, we highlight the feasibility of an extramucosal resection of the endometriotic tissue. This is as an even less invasive approach done laparoscopically that can avoid partial cystectomy in selected cases.

\section{CASE REPORT}

A 35-year-old woman, nulligravida, presented to our clinic with cyclic dysuria, urgency urinary incontinence and increased urinary frequency. Symptoms had started around eight years earlier, and were partially controlled with continuous use of oral contraceptives followed by a levonorgestrel-releasing intrauterine system. In 2014, after discontinuation of hormone therapy, her urinary symptoms resumed and were accompanied by pelvic pain. Endovaginal pelvic ultrasound showed no abnormalities, while a ultrasound mapping for pelvic endometriosis revealed a hypoechoic lesion in the bladder measuring $4.1 \times 1.4 \times 3.0$ centimeters in size, extending to the muscular layer of the bladder and adhering to the right uterine wall, as well as other lesions suggestive of endometriosis in the posterior vaginal fornix, vesicouterine pouch, uterosacral ligaments, uterine serosa and ovaries (Figure 1). Magnetic resonance imaging (MRI) further confirmed these findings (Figure 2). Urinalysis and urine culture were negative.

Figure 1. Suggestive lesion presented in ultrasound mapping for endometriosis.

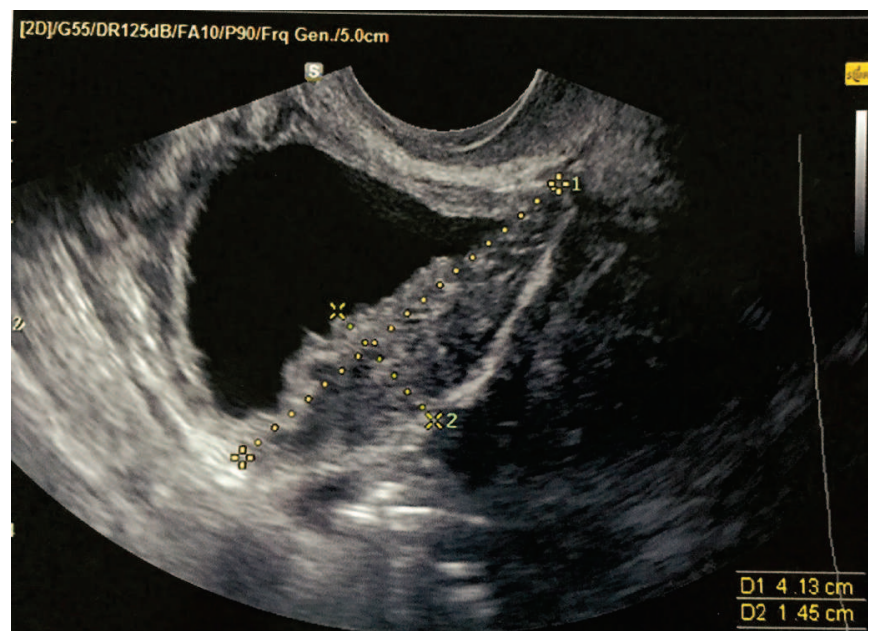

Figure 2. MRI of bladder with lesion suggestive of endometriosis.

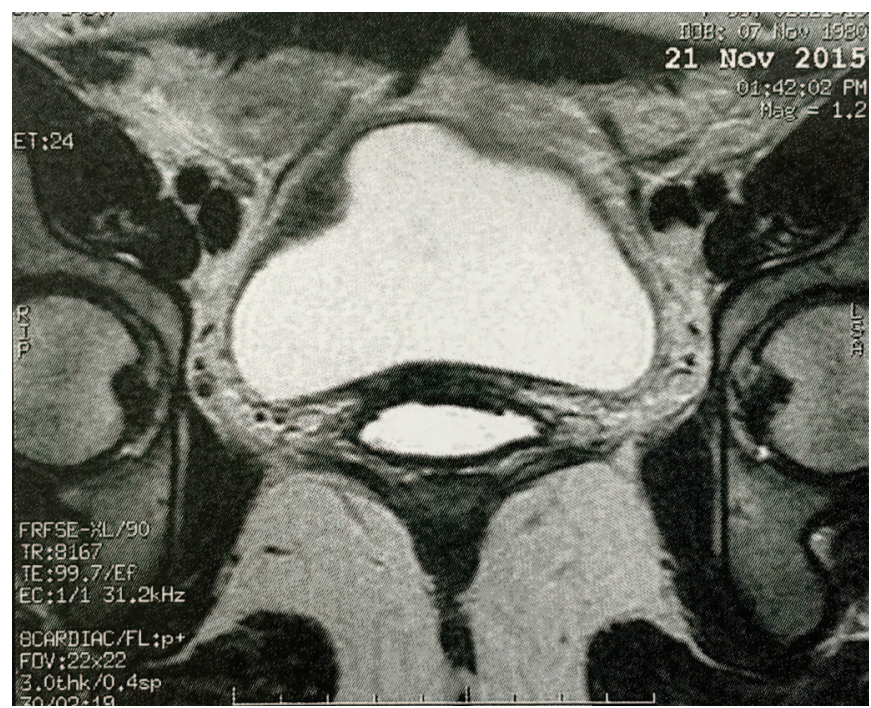

This patient's quality of life was severely affected by her condition. In the perimenstrual period, she had no energy to perform daily activities and felt limited by the pain. Despite of Douglas pouch infiltration, she did not present with dyspareunia at any time during the clinical course of the disease. We then recommended laparoscopic excision of endometriotic nodules and inspection of the abdominopelvic cavity. A few weeks before the scheduled surgery, she presented with increased, continuous pelvic pain, decreased appetite and constipation, which led to anticipation of the procedure.

Intraoperative cystoscopy confirmed the endometriotic lesion but showed no infiltration of the urothelium. The ureteral orifices were located far from the expected surgical area. Laparoscopically, endometriosis of the bladder was detected as a lesion that augmented to $3 \mathrm{~cm}$ on traction. The lesion was attached by well-vascularized dense adhesions to the uterine serosa and was dissected from the anterior wall of the right side of uterus. As part of the bladder resection, the endometriosis lesion was grasped and pulled cranially. Prevesical spaces were accessed using sharp and careful dissection. Thereafter, the bladder was distended and the nodule excised with a Harmonic scalpel. Next, a trac was set on the surrounding peritoneum via bipolar coagulation followed by the retroperitoneal preparation up to the urothelium with a bipolar forceps. The bladder was filled (retrogradely) with blue dye. The lesion was then completely resected on a tangent between the outer endometriosis wall and the back of the urothelium, without opening the urothelium itself. The bladder defect was then closed using musculomuscular single-layer sutures with polygalactin 2-0, through an intracorporeal knotting technique. Closure was tested by instilling methylene blue. The patient was kept on an indwelling catheter 5 days.

Pathologic examination of bladder tissue confirmed the clinical hypothesis of endometriosis. Postoperative recovery went without complication. Approximately one month after 
the procedure, the patient menstruated and presented with no pelvic pain or urinary complaints. A few days after, she was started on a gonadotropin-releasing hormone analogue. Nine months after the operation, the patient remains symptom-free.

\section{DISCUSSION}

Urinary tract endometriosis presents in a variety of ways, including increased urinary frequency, pain on urination and urgency, as well as back pain and asymptomatic loss of renal function. ${ }^{7}$ Although bladder endometriosis is associated with lower urinary tract symptoms in the majority of cases, endometriosis is often underdiagnosed, and a high level of suspicion is necessary. Routine clinical examination findings need to be confirmed through imaging studies, but definitive diagnosis can only be achieved through a biopsy, often requiring a surgical approach. ${ }^{7}$ Furthermore, due to the similarity between symptoms, a diagnosis of interstitial cystitis should always be considered in such patients, and the appropriate exams should be ordered to exclude this condition. ${ }^{1,8}$ In addition, bladder endometriosis should be considered in patients who do not respond to treatment for interstitial cystitis.

Dysuria is a more common symptom in women with urinary tract endometriosis than women without urinary tract infiltration. ${ }^{6}$ Bladder endometriosis is usually suggested by the patient's history, as was the case with the patient presented here. In fact, Abrao et al., Knabben et al. and Fauconnier et al. found an association between the presence of vesical endometriosis and lower urinary tract symptoms. ${ }^{6,9,10}$

Because of the low number of cases and, as a consequence, of randomized trials, management of lower urinary tract endometriosis is controversial. ${ }^{5}$ As with pelvic endometriosis, treatment can be either pharmacological or

\section{REFERÊNCIAS}

1. Prager M, Wilson $\mathrm{T}$, Kruger K, Ebert AD. Laparoscopic extramucosal partial bladder resection in a patient with symptomatic deep-infiltrating endometriosis of the bladder. J Minim Invasive Gynecol. 2012;19(1):113-7.

2. Browne AS, Yu J, Huang RP, Francisco AM, Sidell N, Taylor RN. Proteomic identification of neurotrophins in the eutopic endometrium of women with endometriosis. Fertil Steril. 2012;98(3):713-9.

3. Donnez J, Spada F, Squifflet J, Nisolle M. Bladder endometriosis must be considered as bladder adenomyosis. Fertil Steril. 2000;74(6):1175-81.

4. Vitagliano G, Villeta M, Castillo O. Laparoscopic partial cystectomy in the management of bladder endometriosis: report of two cases. J Endourol. 2006;20(12):1072-4.

5. Antonelli A, Simeone C, Zani D, Sacconi T, Minini G, Canossi E, et al. Clinical aspects and surgical treatment of urinary tract endometriosis: our experience with 31 cases. Eur Urol. 2006;49(6):1093-7; discussion 1097-8. surgical, aiming for the relief of symptoms, the preservation of renal function and the improvement of fertility when desired. ${ }^{8}$ The surgical treatment of bladder endometriosis typically involves partial bladder cystectomy performed through the abdomen, but several approaches have been described, including radical surgery for patients with recurrent, severe disease. On the other hand, transurethral approaches are discouraged due to the risk of bladder injury, since most lesions are transmural. ${ }^{11}$

Partial bladder resection is the most common technique used for endometriosis infiltrating the urothelium. ${ }^{6}$ In a retrospective study with 16 patients with bladder endometriosis, all patients were treated by laparoscopic partial bladder resection, regardless of the location of the vesical endometriotic lesion. Chopin et al also propose that laparoscopic partial cystectomy be the procedure of choice in patients with endometriosis of the bladder, not specifying less invasive procedures even if the endometriotic nodule is considered small. ${ }^{12}$ Kovoor et al, on the other hand, suggested that partial-thickness excision of the detrusor muscle is sufficient in some cases. ${ }^{8}$ Because our patient's vesical lesion was extramucosal, we chose to perform a less invasive approach by shaving the endometriotic lesion laparoscopically, thus avoiding resection of the vesical mucosa. This approach can provide adequate clearance in selected cases, and should be considered in patients with endometriotic lesions that do not invade the urothelium.

\section{CONCLUSION}

Sparing of the bladder mucosa while removing extramucosal endometriosis is an acceptable technique if adequate clearance can be obtained. Postsurgical outcomes in the medium term follow-up show complete improvement of bladder symptoms and pelvic pain, with no recurrence so far.

6. Knabben L, Imboden S, Fellmann B, Nirgianakis K, Kuhn A, Mueller MD. Urinary tract endometriosis in patients with deep infiltrating endometriosis: prevalence, symptoms, management, and proposal for a new clinical classification. Fertil Steril. 2015;103(1):147-52.

7. Gustilo-Ashby AM, Paraiso MF. Treatment of urinary tract endometriosis. J Minim Invasive Gynecol. 2006;13(6):559-65.

8. Kovoor E, Nassif J, Miranda-Mendoza I, Wattiez A. Endometriosis of bladder: outcomes after laparoscopic surgery. J Minim Invasive Gynecol. 2010;17(5):600-4.

9. Abrao MS, Dias JA Jr, Bellelis P, Podgaec S, Bautzer CR, Gromatsky C. Endometriosis of the ureter and bladder are not associated diseases. Fertil Steril. 2009;91(5):1662-7.

10. Fauconnier A, Chapron C, Dubuisson JB, Vieira M, Dousset B, Breart G. Relation between pain symptoms and the anatomic location of deep infiltrating endometriosis. Fertil Steril. 2002;78(4):719-26. 
11. Comiter CV. Endometriosis of the urinary tract. Urol Clin North Am. 2002;29(3):625-35.
12. Chopin N, Vieira M, Borghese B, Foulot H, Dousset B, Coste $\mathrm{J}$, et al. Operative management of deeply infiltrating endometriosis: results on pelvic pain symptoms according to a surgical classification. J Minim Invasive Gynecol. 2005;12(2):106-12.

\section{Como citar:}

Augusto KL, Magalhaes TF, Almeida FC, Freire LM, Bilhar AP, Bezerra LR. Laparoscopic resection of extramucosal vesical endometriosis without partial cystectomy. Rev Med UFC. 2018 abr-jun;58(2):51-54. 